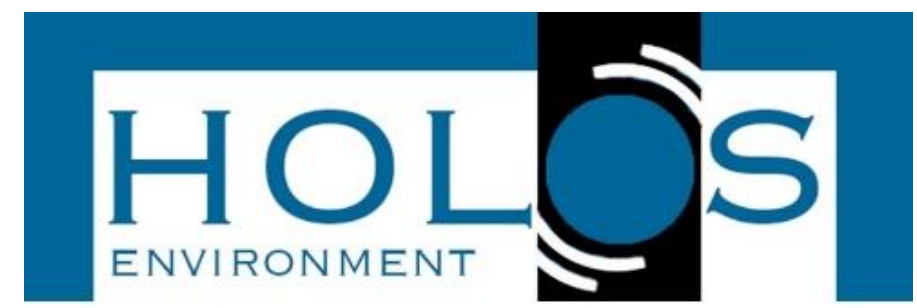

\title{
SANEAMENTO BÁSICO: IMPACTO DO ESGOTO DESPEJADO NA ORLA DE OLINDA-PE
}

\section{BASIC SANITATION: IMPACT OF CLEANING SEWAGE ON OLINDA-PE}

\author{
Kleber José Pinheiro Lins ${ }^{1}$; Micherllaynne Alves Ferreira Lins²
}

Artigo recebido em:30/10/2018 e aceito para publicação em: 14/06/2019.

DOI: http://dx.doi.org/10.14295/holos.v19i2.12318

Resumo: Estudos confirmam que mais de um bilhão de pessoas não têm acesso à habitação segura e serviços básicos de saneamento, ocasionando a proliferação fácil de muitas doenças e degradação do meio ambiente devido a falta do abastecimento de água potável, da rede de esgotamento sanitário e coleta de lixo. Hoje, os esgotos constituem o maior problema de poluição marinha a nível global, tanto em volume de material poluente despejado quanto aos problemas de saúde publica que causam. $\mathrm{O}$ objetivo desse estudo foi descrever sobre saneamento básico e a problemática do esgoto despejado na Orla do Município de Olinda - PE, apresentando um guia para uma Estação de Tratamento de Esgoto. Trata-se de um estudo de caso, de objetivo exploratório e natureza qualitativa, realizada com base em um trecho da Orla do Município de Olinda-PE com despejo de esgoto no mar. Foi possível perceber que grandes são os problemas ambientais e este deve ser visto de maneira global, pelo fato de afetar tanto a vida de seres humanos quanto vegetação e animais. Um dos grandes problemas que estão relacionados à poluição do mar são os dejetos dentre eles destacam-se os componentes, físicos, químicos e biológicos. A Estação de Tratamento de Esgoto (ETE) é uma das soluções que podem evitar a poluição e melhorar a qualidade de vida, assim como, tornar o ambiente mais confortável e agradável a toda população.

Palavras-chave: Esgotos. Meio ambiente. Poluição ambiental.

Abstract: Studies confirm that more than 1 billion people do not have access to safe housing and basic sanitation services, leading to the easy proliferation of many diseases and environmental degradation due to lack of potable water, sewage trash. Today, sewage is the largest marine pollution problem globally, both in the amount of polluting material dumped and the public health problems it causes. The objective of this study was to describe basic sanitation and the problem of sewage discharged at the Olinda Municipality - PE, presenting a guide for a Sewage Treatment Station. This is a case study, with an exploratory objective and qualitative nature, based on a section of the Olinda-PE Municipality, with sewage disposal at sea. It was possible to perceive that great environmental problems are and this must be seen in a global way, because it affects both the lives of humans as well as vegetation and animals. One of the major problems that are related to the pollution of the sea are the wastes among them the components, physical, chemical and biological stand out. The Sewage Treatment Station (ETE) is one of the solutions that can avoid pollution and improve the quality of life, as well as make the environment more comfortable and pleasant to the entire population.

Palavras-chave: Sewage. Environment. Environmental Pollution.

\footnotetext{
1 IPOG, Recife, Pernambuco, Brasil. E-mail: (kleberlins@gmail.com)

2 Faculdade de Integração do Sertão (FIS), Serra Talhada, Pernambuco, Brasil. E-mail: (micherllaynne@hotmail.com)
} 


\section{INTRODUÇÃO}

Para a OMS (Organização Mundial de Saúde) saneamento significa o controle de todos os fatores que se relacionam com o meio ambiente e o homem, caracterizando um conjunto de ações socioeconômicas com o intuito de diminuir ou evitar riscos para os seres humanos e animais (LEAL, 2008).

Para Guimarães, Carvalho e Silva (2007) grandes dos problemas sanitários afetam diretamente a população e estes estão intrinsecamente relacionados com o meio ambiente em que vivemos, podendo um local contaminado ocasionar mortes, sejam elas de pessoas, animais e vegetação.

O pai da Engenharia ambiental, o engenheiro Saturnino de Brito apresentou em 1930 os sistemas de distribuição de água e coleta de esgotos, favorecendo o saneamento e evitando os criadouros e proliferação de insetos. Hoje, esses sistemas funcionam na mesma perspectiva, e ainda estimulam a sociedade e comunidade tecnológica a desenvolver estratégias para melhorar o ambiente proporcionando qualidade de vida aos indivíduos (LEAL, 2008).

Uma pesquisa feita pelo Instituto Trata Brasil em 2013 revelou que no Recife no Estado de Pernambuco, que ocupa o 69이 lugar no ranking, $82 \%$ da população recebe água tratada, mas menos da metade da cidade (35\%) conta com rede de esgoto. Índice inferior é registrado em Olinda, onde 32\% dos moradores têm acesso ao serviço. A pesquisa levou em consideração índices como percentual da população atendida com água tratada, coleta de esgoto, quantidade de esgoto tratado, vazamentos de água e investimentos (ITB, 2013).

A estatística descrita estimula pensar qual a preocupação dos governantes sobre tal temática e quais as estratégias de melhoria do sistema de saneamento básico podem ser aplicadas em localidades carentes ou que poluem o meio ambiente. A exemplo, diariamente são despejados na orla de Olinda em um trecho de 4,9 km de extensão, cerca de 827 mil litros de dejetos (cálculo baseado de acordo com a NBR Norma Brasileira) 7229 e NBR 12209 oriundos de esgoto sanitário, causando assim poluição marinha, mortes de animais aquáticos, impossibilitando a utilização para banhistas nesse trecho.

Observando essa realidade é necessário se pensar em técnicas e abordagens para melhorar a qualidade de vida dos seres que utilizam este ambiente para viver. Pensando nisso, uma boa estratégia seria a construção de uma ETE - Estação de 
Tratamento de Esgoto que tem como objetivo o esgotamento sanitário que através de processos físicos, químicos ou biológicos retiram as cargas poluentes do esgoto, devolvendo ao ambiente a água tratada, em conformidade com os padrões exigidos pela legislação ambiental.

Uma das razões que impulsionaram a escolha da temática foi à problemática apresentada, pois o despejo de dejetos em ambientes impróprios pode causar diversos problemas, não só ao homem como também ao meio ambiente. A fim de impulsionar os conhecimentos dentro da especialização em engenharia ambiental e propor estratégias para solucionar o problema, esse trabalho tem como intuito apresentar uma construção de uma estação de tratamento de esgoto solucionando definitivamente os problemas aqui apresentados.

Este estudo torna-se factível pela necessidade de extinguir a agressão ao meio ambiente no local estudado, tendo em vista que o único meio de poluição marinha é oriunda do esgoto despejado diretamente sem tratamento no mar.

O objetivo desse estudo é descrever sobre saneamento básico e a problemática do esgoto despejado na Orla do Município de Olinda - PE, apresentando um guia para uma Estação de Tratamento de Esgoto, com características como: separar o material contaminado da água que deverá ser devolvida ao mar de forma pura $(99,9 \%)$ e reaproveitar o dejeto para fins de adubo orgânico.

\section{MATERIAIS E MÉTODOS}

O estudo foi realizado no município de Olinda - PE, no trecho de (- 8.011473, - 34.842357 ao -7.969206, - 34.831304). O município de Olinda possui de acordo com o IBGE (Instituto Brasileiro de Geografia e Estatística) uma população estimada (2016) em 390.144 habitantes, tendo em sua tangência uma ETE no Bairro de Peixinhos o que não comporta o volume da cidade como um todo. $O$ estudo está direcionado na Orla de Olinda-PE.

Trata-se de um estudo de caso, de objetivo exploratório e natureza qualitativa. Para Gil (1996), Berto e Nakano (2000) o estudo de caso é um estudo de natureza empírica que investiga um determinado fenômeno, geralmente contemporâneo, dentro de um contexto real de vida, quando as fronteiras entre o fenômeno e o contexto 
em que ele se insere não são claramente definidas. Trata-se de uma análise aprofundada de um ou mais objetos (casos), para que permita o seu amplo e detalhado conhecimento.

Em um primeiro momento foi realizado uma visita nesse trecho mencionado contabilizando os imóveis ali presentes, calculando de acordo com as respectivas NBR's 7229 e 12209 o volume de esgoto que é despejado no mar, estimativa esta, utilizada para a primeira fase do projeto reconhecendo o problema. No segundo passo, diz respeito ao estudo do impacto ambiental e principais consequências para o homem e o meio ambiente, realizada através de revisão da literatura numa abordagem exploratória de publicações de cunho científico obedecendo os anos de 2001 a 2016. Após esse procedimento foi colhido dados referente aos aspectos atuais do cenário da Orla de Olinda na Secretaria do Meio Ambiente de Olinda no Estado de Pernambuco.

Ao final foi apresentado mediante fatos científicos um passo a passo para a construção de uma Estação de Tratamento de Esgoto. No contexto de divulgação dos resultados de pesquisa, o presente trabalho será apresentado ao gestor local. Foi elaborado uma possível solução para a problemática de esgoto na Orla com base numa construção de uma Estação de Tratamento de Esgoto a qual possui características como: separar o material contaminado da água que deverá ser devolvida ao mar de forma pura e reaproveitar o dejeto para fins de adubo orgânico.

Este estudo não traz riscos nem benefícios financeiros, por não envolver seres humanos. Também não há a necessidade de uma submissão ao comitê de ética em pesquisa, tornando-se um projeto de intervenção de aplicabilidade posterior.

\section{RESULTADOS E DISCUSSÃO}

\subsection{Saneamento Básico}

Não é de hoje que se pensa na logística do saneamento básico. Durante a revolução Industrial, houve um significativo aumento dos relatos das doenças associadas ao ambiente e que essas doenças desenvolvidas por falta do saneamento levavam a morte. Muito antes disso, sabendo que a doença surgiria do ambiente algumas 
civilizações já praticavam o saneamento, por exemplo, a Índia em 3.750 a.C construíram as primeiras galerias de esgoto, na Babilônia em 3.100 a.C. foram utilizadas manilhas de cerâmica para canalizar o esgoto.

Para que se tenha saneamento básico muitas são as ferramentas que devem constituir a infraestrutura do local seja ela física ou educacional. Os serviços que englobam o sistema de saneamento básico são: abastecimento de água às populações, com a qualidade compatível com a proteção de sua saúde e em quantidade suficiente para a garantia de condições básicas de conforto; coleta, tratamento e disposição ambientalmente adequada e sanitariamente segura de águas residuais (esgotos sanitários, resíduos líquidos industriais e agrícolas); acondicionamento, coleta, transporte e destino final dos resíduos sólidos (incluindo os rejeitos provenientes das atividades doméstica, comercial e de serviços, industrial e pública); coleta de águas pluviais e controle de empoçamentos e inundações; controle de vetores de doenças transmissíveis (insetos, roedores, moluscos, etc.); saneamento dos alimentos; saneamento dos meios de transportes; saneamento e planejamento territorial; saneamento da habitação, dos locais de trabalho, de educação, de recreação e dos hospitais; controle da poluição ambiental - água, ar, solo, acústica e visual.

A tabela 1 descreve as características e parâmetros utilizados como base para conhecer os principais poluentes e as consequências dessa contaminação.

Tabela 1 - Descrição sobre poluentes, parâmetros, tipo de efluente e consequências (continua)

\begin{tabular}{|c|c|c|c|}
\hline Poluentes & $\begin{array}{l}\text { Parâmetros de } \\
\text { caracterização }\end{array}$ & $\begin{array}{l}\text { Tipo de } \\
\text { efluente }\end{array}$ & Consequências \\
\hline Sólidos em suspensão & Sólidos em suspensão totais & $\begin{array}{l}\text { Domésticos } \\
\text { Industriais }\end{array}$ & $\begin{array}{l}\text { Problemas estéticos } \\
\text { Depósitos de lodo } \\
\text { Adsorção de poluentes } \\
\text { Proteção de patogênicos }\end{array}$ \\
\hline Sólidos flutuantes & Óleos e graxas & $\begin{array}{l}\text { Domésticos } \\
\text { Industriais }\end{array}$ & Problemas estéticos \\
\hline $\begin{array}{l}\text { Matéria orgânica } \\
\text { biodegradável }\end{array}$ & $\begin{array}{l}\text { Demanda bioquimica de } \\
\text { oxigênio (DBO) }\end{array}$ & $\begin{array}{l}\text { Domésticos } \\
\text { Industriais }\end{array}$ & $\begin{array}{l}\text { Consumo de oxigênio } \\
\text { Mortandade de peixes } \\
\text { Condições sépticas }\end{array}$ \\
\hline Patogênicos & Coliformes & Domésticos & Doenças de veiculação hidrica \\
\hline Nutrientes & $\begin{array}{l}\text { Nitrogênio } \\
\text { Fósforo }\end{array}$ & $\begin{array}{l}\text { Domésticos } \\
\text { Industriais }\end{array}$ & $\begin{array}{l}\text { Crescimento excessivo de } \\
\text { algas } \\
\text { Toxicidade aos peixes } \\
\text { Doença em recém-nascidos } \\
\text { (nitratos) }\end{array}$ \\
\hline $\begin{array}{l}\text { Compostos não } \\
\text { biodegradáveis }\end{array}$ & $\begin{array}{l}\text { Pesticidas } \\
\text { Detergentes } \\
\text { Outros }\end{array}$ & $\begin{array}{l}\text { Industriais } \\
\text { Agricolas }\end{array}$ & $\begin{array}{l}\text { Toxicidade e espumas } \\
\text { Redução de transferência de } \\
\text { oxigênio } \\
\text { Não biodegradabilidade } \\
\text { Maus odores }\end{array}$ \\
\hline
\end{tabular}


Tabela 1 - Descrição sobre poluentes, parâmetros, tipo de efluente e consequências (conclusão)

\begin{tabular}{llll}
\hline Poluentes & $\begin{array}{l}\text { Parâmetros de } \\
\text { Caracterização }\end{array}$ & $\begin{array}{l}\text { Tipo de } \\
\text { efluente }\end{array}$ & Consequências \\
\hline Metais pesados & $\begin{array}{l}\text { Elementos especificos (ex: arsênio, } \\
\text { cádmio, cromo, mercúrio, zinco, etc) }\end{array}$ & Industriais & $\begin{array}{l}\text { Toxicidade } \\
\text { Inibição do tratamento } \\
\text { biológico dos esgotos } \\
\text { Problemas de disposição do } \\
\text { lodo na agricultura } \\
\text { Contaminação da água } \\
\text { subterrânea }\end{array}$ \\
$\begin{array}{l}\text { Sólidos } \\
\text { inorgânicos } \\
\text { dissolvidos }\end{array}$ & $\begin{array}{l}\text { Sólidos dissolvidos totais } \\
\text { Condutividade elétrica }\end{array}$ & Reutilizados & $\begin{array}{l}\text { Salinidade excessiva - prejuizo } \\
\text { às plantações (irrigação) } \\
\text { Toxicidade a plantas (alguns } \\
\text { ions) }\end{array}$ \\
& & $\begin{array}{l}\text { Problemas de permeabilidade } \\
\text { do solo (sódio) }\end{array}$ \\
\hline
\end{tabular}

\subsubsection{Impactos do Esgoto Para a Sociedade e Meio Ambiente}

O esgoto é considerado uma mistura de água e matéria orgânica, no qual estão presentes as fezes, urina e água do serviço doméstico, podendo $99 \%$ do volume do esgoto ser água e apenas $1 \%$ ser matéria orgânica, e o objetivo principal de um tratamento de esgoto é desfazer essa mistura (GOMES, MELO, VALE, 2005).

Quando não há a rede coletora de esgoto a população utiliza fossa séptica ou usa esgoto diretamente associado à valões, córregos, rios e praias. Porém, são atividades como estas que irão contribuir para o agravamento e contaminação do meio ambiente.

Até o início do século $X X$ a população não tinha nenhuma estrutura sanitária e lançava seus dejetos diretamente nas ruas, nos fundos dos quintais, terrenos baldios, nas praias. Hoje não é muito diferente, muitos desses lugares continuam sendo alvo para receber os desejos, principalmente nas praias, em que as construções favorecem o esgotamento do esgoto no mar, pois os prédios estão posicionados voltados para o mar (PHILIPPI Jr, 2004).

O marco das intervenções públicas em relação aos esgotos da cidade data de 1913, quando tiveram início as obras do primeiro sistema de esgotamento sanitário de Florianópolis. Entretanto, algumas ações anteriores se destacam pelo seu caráter estrutural. O sistema compunha-se de um conjunto de redes coletoras, a partir das quais os esgotos eram encaminhados à estação de tratamento, por gravidade ou através de bombeamento feito por três estações elevatórias (SOBRINHO, TSUTIYA, 2011).

O grande problema do despejo de esgoto sem tratamento nos rios, lagos e mares é porque afeta a qualidade das águas e tornam-se um problema ambiental, social e de saúde pública. Para o Instituto Trata Brasil, em pesquisa realizada no ano 
de 2011 , refere que o esgoto produzido no país $38 \%$ deste passa por algum tipo de tratamento. O que significa que mais de 100 milhões de brasileiros, não possui acesso aos serviços de saneamento básico e todo esgoto produzido por essa população que é despejado em nossos mananciais. O levantamento, intitulado Ranking do Saneamento mostra que a coleta de esgotos chegou a $61,40 \%$ da população nas 100 maiores cidades do Brasil e à somente $48,1 \%$ no restante do país.

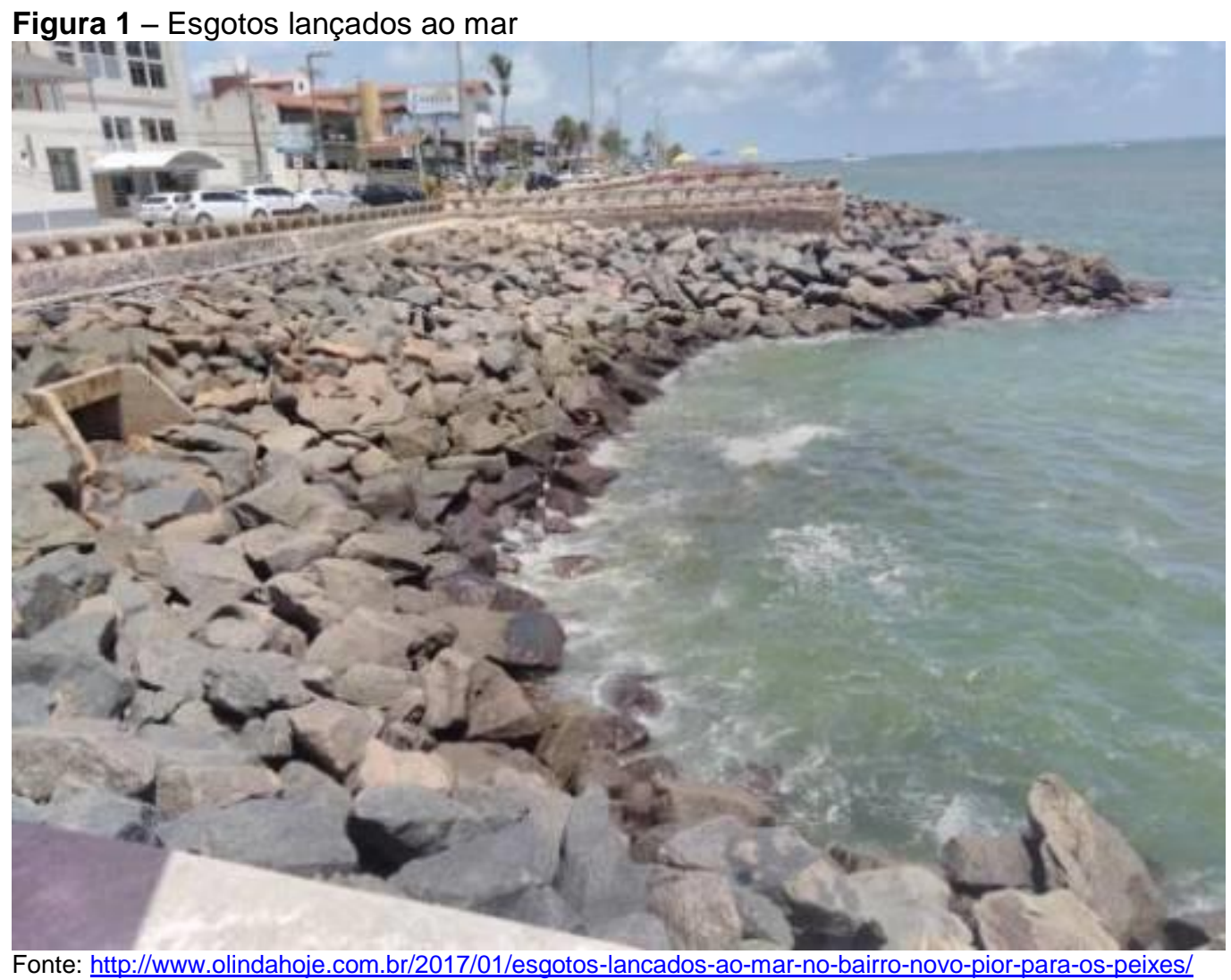

O esgoto bruto para atender as exigências legais passa por diferentes níveis de tratamento: preliminar e biológico. Em algumas situações específicas pode ser realizado o tratamento físico-químico e a desinfecção do esgoto tratado. Durante o processo de tratamento de esgoto ocorre a formação de lodo e de gases que podem ser submetidos a tratamentos específicos (SOBRINHO, TSUTIYA, 2011).

Para Baptista Neto, Wallner-Kersanach, Patchineelam (2008) o crescimento na zona urbana tem propiciado o desenvolvimento econômico assim como aumentado a produção de esgotos, sejam eles domésticos ou comerciais. Te sido um fator preocupante a contaminação causada pelo esgoto nas áreas costeiras, até porque muitas cidades e regiões ainda não possuem uma estação de tratamento adequada. 
É bem mais fácil e viável às entidades governamentais lançar o esgoto no mar se comparado à construção de uma ETE, essa pois, possui um custo bem elevado. Esse tipo de atitude provoca a morte principalmente da vida marinha, muitos dos organismos não sobrevivem por longo tempo em ambientes marinhos, especialmente devido à ação das radiações solares, temperatura, salinidade, predação e competição e antibióticos produzidos por organismos marinhos, enquanto muitos patógenos podem sobreviver por mais tempo sob tais condições e representar risco potencial à saúde publica. Além das bactérias, alguns vírus podem sobreviver aos processos convencionais de tratamento das águas e de esgoto (BAPTISTA NETO, WALLNERKERSANACH, PATCHINEELAM, 2008).

Figura 2 - Contaminação com coliformes fecais

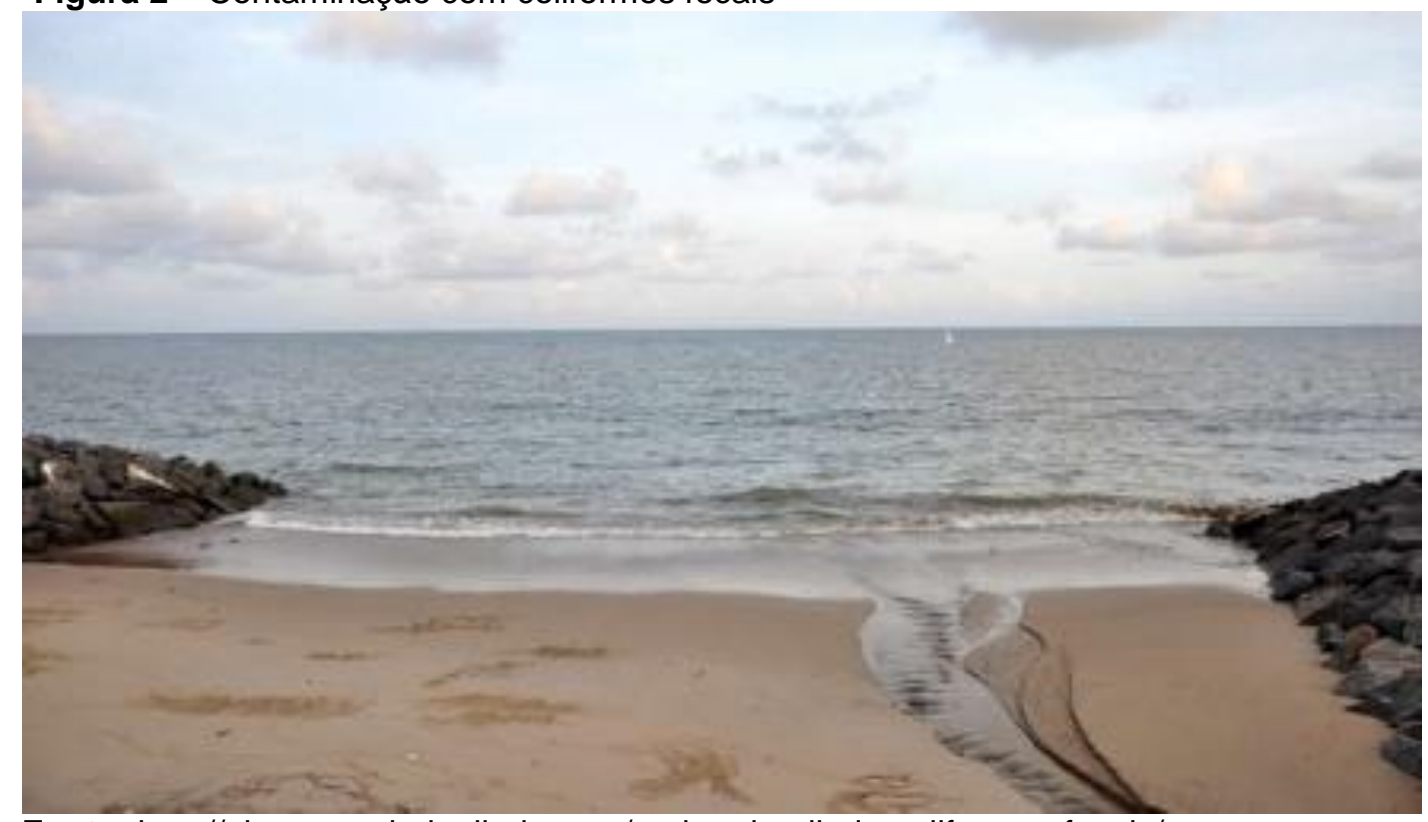

Fonte: http://observatoriodeolinda.com/praias-de-olinda-coliformes-fecais/

Para que uma ETE seja implantada e implementada é necessário seguir algumas especificações como: Resolução CONAMA 357/2005 (Dispõe sobre a classificação dos corpos de água e diretrizes ambientais para o seu enquadramento, bem como estabelece as condições e padrões de lançamento de efluentes, e dá outras providências).

Resolução CONAMA 375/2006 (Define critérios e procedimentos, para o uso agrícola de lodos de esgoto gerados em estações de tratamento de esgoto sanitário e seus produtos derivados, e dá outras providências); Resolução CONAMA № 
377/2006 (Dispõe sobre licenciamento ambiental simplificado de Sistemas de Esgotamento Sanitário); Resolução CONAMA № 380/2006 (Retifica a Resolução CONAMA № 375/2006 - Define critérios e procedimentos, para o uso agrícola de lodos de esgoto gerados em estações de tratamento de esgoto sanitário e seus produtos derivados, e dá outras providências); Resolução CONAMA № 397/2008 (Altera o inciso II do § 40 e a Tabela $X$ do § 5o, ambos do art. 34 da Resolução do Conselho Nacional do Meio Ambiente); CONAMA no 357, de 2005, (que dispõe sobre a classificação dos corpos de água e diretrizes ambientais para o seu enquadramento, bem como estabelece as condições e padrões de lançamento de efluentes).

Figura 3 - Estação de Tratamento de Esgoto

Fonte: https://www.saneamentobasico.com.br/ete-operada-pela-brk-iso-14001/

\subsection{Levantamento de informações e coleta de dados}

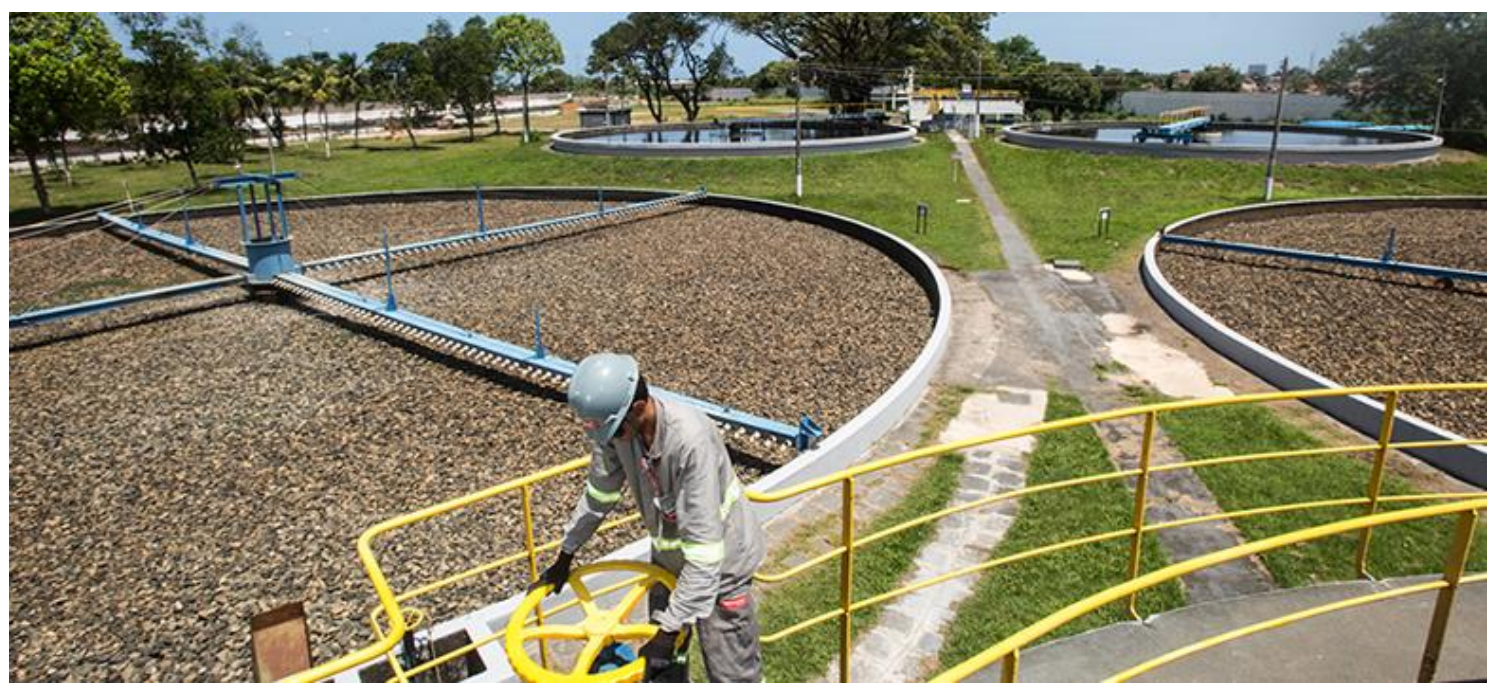

$\mathrm{Na}$ análise macroscópica do trecho contaminado:

- Odor da água: Presença de constituintes inorgânicos em concentrações elevadas tais como o ferro, cloreto, sulfato, gás sulfídrico e presença de compostos orgânicos originários de fontes antropogênicas (fenóis, nitrofenóis) e demais compostos aromáticos (tetracloreto de carbono, tetracloroetileno, etc);

- Materiais flutuantes: presença de objetos na superfície da água como graxas, espumas, óleos e coliformes fecais;

- Uso antrópico: evidência de utilização por humanos, banho de mar e presença de animais marinhos. 
- Identificação: não foi encontradas placas ou similar indicando a existência da nascente no local ou informações educativas relacionadas ao esgoto.

- Residências: Foram encontrados 72 edifícios, 103 casas, 12 hotéis e 22 restaurantes no trecho estudado.

\subsection{Tratamento de esgoto com base em uma ETE}

\subsubsection{Tratamento Preliminar}

Tem por objetivo a remoção de sólidos grosseiros e em suspenção tipo areia, papéis, plásticos, cabelos, e outros resíduos que seguem pelas tubulações devido ao uso incorreto do vaso sanitário e redes coletoras de esgoto. Para separar esse material o tratamento preliminar é constituído de tanques desarenadores e gradeamento (CESAN, 2013).

\subsubsection{Tratamento Biológico}

Existem vários tipos de tratamento de esgoto doméstico. Processos biológicos, aeróbios e anaeróbios são aplicados com uma série de aspectos positivos e negativos. Esses processos utilizam organismos que se proliferam na água, otimizando o tratamento e minimizando custos, para que se consiga a maior eficiência possível. A seguir são apresentadas algumas modalidades utilizadas (CEZAN, 2013).

1) Lagoa de Estabilização: Os Sistemas de Lagoas de Estabilização constituemse na forma mais simples para o tratamento dos esgotos. Há diversas variantes dos sistemas de lagoas de estabilização com diferentes níveis de simplicidade operacional e requisito de área. O tempo de detenção hidráulica do esgoto, que é o tempo de passagem do esgoto pelo sistema, pode variar de 15 até 25 dias para remoção da matéria orgânica e devolução do efluente à natureza. Lagoa de estabilização trata-se de uma tecnologia simples, mas que precisa de grandes áreas para sua implantação, o que em muitos casos é difícil de encontrar dentro de grandes cidades muito urbanizadas. O esgoto chega à lagoa onde há uma grande quantidade de micro-organismos aeróbios (que dependem de oxigênio) e permanecem ali até que o processo de decomposição da matéria 
orgânica termine e o esgoto tratado (efluente) possa ser devolvido a um corpo receptor: córrego, rio ou praia. b) Reator Anaeróbio de Fluxo Ascendente (RAFA) ou Reator UASB É um reator fechado onde o tratamento biológico ocorre por processo anaeróbio, isto é, sem oxigênio. $O$ esgoto entra pela base do reator, passa por uma manta de micro-organismos anaeróbicos onde ocorre a decomposição da matéria orgânica. O esgoto tratado e coletado pelas calhas na parte superior. Trata-se de uma tecnologia que ocupa pouco espaço, sendo indicada para centros urbanos, bairros, vilas etc. Por se tratar de um sistema fechado, há liberação de gás que é coletado e queimado. c) Lodo Ativado: O esgoto ao chegar à estação é encaminhado para um tanque onde é submetido à aeração. A quantidade de oxigênio introduzido na mistura através dos aeradores propicia o desenvolvimento de bactérias aeróbias que irão digerir a matéria orgânica carbonácea e a nitrificação do nitrogênio orgânico total remanescente do afluente bruto. A atuação de micro-organismos específicos, forma flocos denominados lodo ativado ou lodo biológico. Parte do lodo retorna ao processo e a outra parte é enviada para desague e destinação em aterro ou outro tratamento específico. O efluente tratado é enviado para o rio (ANDREOLI, 2001; CEZAN, 2013).

2) Desinfecção do Efluente (Esgoto Tratado) para devolução do esgoto tratado à natureza é necessário que seja atendido e definido à Legislação Ambiental por isso o efluente é submetido ao processo de desinfecção através de lâmpadas ultravioleta (UV). Quando o efluente entra em contato com a radiação UV os micro-organismos são esterilizados impedindo sua reprodução (ANDREOLI, 2001; CEZAN, 2013).

3) Lodo de Esgoto: O lodo é resultado do processo de decomposição da matéria orgânica presente no esgoto. Este processo é realizado pelos micro-organismos, principalmente bactérias. Visando reduzir a umidade do lodo de esgoto este é submetido ao processo de deságue e dependendo da tecnologia utilizada ele pode apresentar características semissólida/pastosa ou sólida. Em função de suas características, ser orgânico e rico em nutrientes, o lodo de esgoto pode ser utilizado na agricultura uma vez que traz diversos benefícios 
como o aumento da fertilidade e teor de matéria orgânica no solo, contribuindo para o aumento da produtividade (BETTIOL, CAMARGO, 2006; CEZAN, 2013).

4) Tratamento de emissões de compostos orgânicos voláteis e odores: As instalações de tratamento de esgotos sanitários podem gerar odores em função dos processos adotados e das condições operacionais empregadas. Neste caso faz-se necessário a implementação de soluções sustentáveis. O sistema Biofiltro é uma das soluções utilizadas para tratar as emissões. Neste os gases componentes das emissões são degradados biologicamente por micro-organismos presentes em um leito de biomassa. Lixo: Materiais como plásticos, papéis, restos de comida, pó de café, areia de praia e outros sólidos costumam provocar o desgaste de equipamentos de uma ETE, Estações Elevatórias e entupimento da rede de esgoto causando alagamento em ruas e até retorno dos dejetos para dentro do imóvel. O cabelo e o fio dental são responsáveis por danos aos aeradores (equipamentos que fazem a aeração do esgoto), nas lagoas de estabilização provocando a redução da eficiência do tratamento (ANDREOLI, 2001; CEZAN, 2013).

5) Gordura: A gordura resultante de frituras e restos de alimentos quando despejado pelo ralo da pia, seguem pelas tubulações das residências e redes coletoras podendo com o tempo se solidificar reduzindo o diâmetro da tubulação provocando o entupimento e retorno dos dejetos. Por isso a importância de uma caixa interna no imóvel, conectada a pia, chamada caixa de gordura que deve ser limpa de tempo em tempo conservando assim as instalações do imóvel e da rede de esgoto (ANDREOLI, 2001; CEZAN, 2013).

6) Desague: após todo processo de tratamento na ETE a água tratada é devolvida ao mar ou até mesmo aos rios com pureza de $99,9 \%$ sem riscos ao meio ambiente ou ao homem.

\section{CONCLUSÃO}

O presente estudo apresentou as principais características do desague do es- 
goto na Orla, assim como, a referência do tipo de contaminação, os aspectos contaminantes e qual solução para melhoria desse estado.

Foi ressaltado a importância de se ter uma ETE para tratar o esgoto sanitário da orla de Olinda no trecho pesquisado, pois a agressão ao meio ambiente e ao homem tem ocorrido a vários anos, prejudicando assim a vida marinha e a qualidade de vida dos banhistas que moram e frequentam essa praia.

O estudo também descreveu os principais aspectos relacionados ao saneamento básico evidenciando que a falta deste ainda é um fator preocupante à saúde pública, pois está sinalizado pelo processamento de doenças vinculadas ao lixo e não tratamento de esgoto.

Espera-se que esse estudo venha a contribuir cientificamente para adoção de medidas sanitárias preventivas e conscientização do governo/estado para que possamos despoluir as áreas afetadas, principalmente no que diz respeito ao trecho estudado por ser uma região turística.

\section{REFERÊNCIAS}

ANDREOLI, V. Resíduos sólidos do saneamento: processamento, reciclagem e disposição final . Rio de Janeiro: RiMa, ABES, 2001.

BAPTISTA NETO, J.A.; WALLNER-KERSANACH, M E PATCHINEELAM, S.M., 2008. Poluição marinha. 1. ed. Rio de Janeiro: Interciência.

BARROS, R.T.V et al. Saneamento. Belo Horizonte : Escola de Engenharia da UFMG, 1995. 221 p. (Manual de Saneamento e Proteção Ambiental para os Municípios, 2)

BETTIOL, W; CAMARGO, AO. Lodo de esgoto: impactos ambientais na agricultura. Jaguariúna: Embrapa Meio Ambiente, 2006. 349 p.

BERTO, RMVS., NAKANO, DNA. Produção científica nos anais do encontro nacional de engenharia de produção: um levantamento de métodos e tipos de pesquisa. Produção, v. 9, n. 2, p. 65-76, 2000. https://doi.org/10.1590/S0103-65131999000200005

BRASIL. ABNT (Associação Brasileira de Normas Técnicas). NBR 7229: Projeto, construção e operação de sistemas de tanques sépticos. Setembro de 1993.

BRASIL. ABNT (Associação Brasileira de Normas Técnicas). NBR 7229: Elaboração de projetos hidráulico-sanitários de estação de tratamento de esgoto sanitário. 2. ed. 2011.

BRASIL. ABNT (Associação Brasileira de Normas Técnicas). NBR 1209: Projeto de estações de tratamento de esgoto sanitário. Projeto 02:009.27-005/1989. ABR 1992.

CESAN. Apostila tratamento de esgoto. Estação de Tratamento de Mulembá - Vitória. Revisada em Julho de 2013. Disponível em: http://www.cesan.com.br/wp-content/uploads/2013/08/APOSTILA TRATAMENTO ESGOTO.pdf Acesso em: 16 set. 2017. 
CONAMA. Resolução no 357, de 17 de março de 2005. Dispõe sobre a classificação dos corpos de água e diretrizes ambientais para o seu enquadramento, bem como estabelece as condições e padrões de lançamento de efluentes, e dá outras providências. Alterada pela Resolução 410/2009 e pela 430/2011. 2005.

CONAMA. Resolução CONAMA no 377, de 9 de outubro de 2006. Dispõe sobre licenciamento ambiental simplificado de Sistemas de Esgotamento Sanitário. Publicada no DOU no 195, de 10 de outubro de 2006, Seção 1, página 56. 2006.

CONAMA. Resolução no $\mathbf{3 7 5}$, de 29 de agosto de 2006. Define critérios e procedimentos, para o uso agrícola de lodos de esgoto gerados em estações de tratamento de esgoto sanitário e seus produtos derivados, e dá outras providências. Publicação - Diário Oficial da União 30/08/2006.

CONAMA. Resolução CONAMA no 380, de 31 de outubro de 2006. Retifica o Anexo I da Resolução CONAMA no 375/06. Retifica a Resolução CONAMA no 375/06 - Define critérios e procedimentos para o uso agrícola de lodos de esgoto gerados em estações de tratamento de esgoto sanitário e seus produtos derivados, e dá outras providências. Publicada no DOU no 213, de 7 de novembro de 2006, Seção 1, página 59.

CONAMA. Resolução CONAMA no 397, de 3 de abril de 2008. Altera o inciso II do $\S 40$ e a Tabela X do $\S 5^{\circ}$, ambos do art. 34 da Resolução do Conselho Nacional do Meio AmbienteCONAMA no 357 , de 2005, que dispõe sobre a classificação dos corpos de água e diretrizes ambientais para o seu enquadramento, bem como estabelece as condições e padrões de lançamento de efluentes. Publicada no DOU no 66, de 7 de abril de 2008, Seção 1, páginas 68-69. 2008.

GIL, A. C. Como elaborar projetos de pesquisa. São Paulo: Atlas, 1996.

GOMES, PM.; MELO, C.; VALE, VS. Avaliação dos impactos ambientais em nascentes na cidade de Uberlândia-MG: análise macroscópica. Sociedade \& Natureza, Uberlândia, v. 17, n. 32, p.103-120, jun. 2005

GUIMARÃES, A. J. A.; CARVALHO, D. F. de; SILVA, L. D. B. da. Saneamento básico. Disponível em: <http://www.ufrrj.br/institutos/it/deng/leonardo/ downloads/APOSTILA/Apostila\%20IT\%20179/Cap\%201.pdf> . Acesso em: 15 ago. 2017.

ITB. Instituto Trata brasil. Saneamento é saúde. Notícias ITB. Disponível em: http://www.tratabrasil.org.br/pesquisa-aponta-que-65-do-recife-nao-conta-com-rede-de-esgoto-g1-ri-pernambuco. Acesso em: 12 set. 2017.

LEAL, F. C. T. Juiz de Fora. 2008. Sistemas de saneamento ambiental. Faculdade de Engenharia da UFJF. Departamento de Hidráulica e Saneamento. Curso de Especialização em análise Ambiental. 4 ed. 2008. Notas de Aula.

PHILIPPI Jr., A. Saneamento, saúde e ambiente: fundamentos para um desenvolvimento sustentável. Barueri: Ed. Manole, 2004. Coleção Ambiental.

PREZI. Historia da implantação das estações de tratamento de esgoto. Disponível em: https://prezi.com/usv165xh2bii/historia-da-implantacao-das-estacoes-de-tratamento-de-esgoto/ Acesso em: 02 set. 2017. 
SOBRINHO, PA.; TSUTIYA, MT. Coleta e transporte de esgoto sanitário. 2. ed. p.548. Fundo editorial. 2011. 